\title{
12. Branding 007: Title Sequences in the James Bond Films
}

\author{
Jan-Christopher Horak
}

\begin{abstract}
The James Bond series has maintained its brand identity through the James Bond character, recurring plot elements, and its film design, in particular the credits sequences of Maurice Binder, Robert Brownjohn, MK12, and Daniel Kleinman. This chapter will examine the work of Binder, who created fourteen of the first eighteen Bond titles and has been rightly singled out as one of a new generation of title designers who utilized modernist aesthetics to create a specific look for the James Bond franchise. The chapter also asks how the digital turn, which coincided with the transition from Binder to Kleinman in the 1990s, has impacted the design and aesthetics of the James Bond title sequences.
\end{abstract}

Keywords: Maurice Binder; Daniel Kleinman; title sequences; modernism; branding

The James Bond film series is one of the longest running and most successful film franchises in the history of the movies, now encompassing twenty-four plus two films that have been produced over more than fifty-five years. Having featured no less than six different actors (Sean Connery, George Lazenby, Roger Moore, Timothy Dalton, Pierce Brosnan, and Daniel Craig), the Bond series has maintained its brand identity through the character of James Bond as conceptualized by Ian Fleming, through rigorously recurring plot elements-Bond chasing international bad guys and bedding down a number of beautiful young women-and through the films' design, in particular the credits sequences of Maurice Binder, Robert Brownjohn (briefly), MK 12 (one film) and Daniel Kleinman. Maurice Binder, who created fourteen of the first eighteen Bond titles, starting with $\operatorname{Dr}$. No (UK: Terence

Verheul, J. (ed.), The Cultural Life ofJames Bond:Specters of oo7. Amsterdam: Amsterdam University Press, 2020 DOI 10.5117/9789462982185_CH12 
Young) in 1962, has been rightly singled out as one of a new generation of title designers who utilized modernist design to create a specific look for the Bond franchise, and who influenced the creation of music videos through his marriage in the title sequences of abstract images and catchy pop music tunes. Binder made the latter claim himself in 1991, noting that his sequences "were really the fore-runners of today's pop videos: the song came first and we'd illustrate it" (King 2004; Cork and Scivally 2002, 193).

Maurice Binder's death in 1991 coincided with the end of both the analog era and the Cold War, leading the franchise's producers to hire Daniel Kleinman for 1995's GoldenEye (UK/USA: Martin Campbell), whose seven titles in the Bond series are interrupted only by MK12's equally accomplished title design for Quantum of Solace (UK/USA: Marc Forster, 2008). The titles by Kleinman and MK12 have been praised for their redesign for the digital era, creating dense montages that brand the films and the series while relinquishing the simplicity of modernist design for post-modern pastiches. Kleinman and MK12 conceptualize their titles as surrealistic dreamscapes that incorporate the visual themes of the film that follows. In contrast, Binder's titles promoted the Bond brand, obsessively repeating motifs and technologies but always within the framework of a modernist grid-based design whose goal is the simplification of form. Indeed, after the first half dozen Bond films, Binder's titles were seemingly produced by rote. Ben Radatz (2012), co-director of Quantum of Solace's titles, excuses the repetition of tropes, themes, and technologies, preempting any reservations or negative interpretations:

In spite of the tropes, the Bond titles are not formulaic - they have become a genre unto themselves, and as such they hold a certain immunity from criticisms aimed at its format. To criticize a Bond title for featuring silhouettes is to criticize a Tolkien novel for featuring hobbits.

Ironically, while there has been praise for the Bond titles in some quarters, much of the popular literature on James Bond fails to even mention, much less analyze the work of Binder and Kleinman. Other commentators, including John Brosnan, touch on the themes found in this laudatory statement by John Cork and Bruce Scivally $(2002,48)$ : "Binder's titles, like the films themselves, were marked by elegance, wit and sex. His use of rich color and nude female silhouettes quickly became a celebrated design motif, imitated but never equaled."

Only recently have academics critiqued the deep misogyny of Binder's images. In their discussion of Goldfinger (UK: Guy Hamilton, 1964), Tony Bennett and Janet Woollacott $\left(1987,15^{2-3}\right)$ discuss the sexism of Brownjohn's 
title sequence, citing Laura Mulvey and connecting it to a "long tradition in mainstream Hollywood cinema, whereby women are constructed in terms of erotic spectacle"-but their analysis excludes typography and spatial design. Kristin Hunt (2011, 62), in her Freudian-feminist analysis of dance in the Bond films, goes one step further, comparing Binder's title sequences to a striptease spectacle. Finally, Sabine Planka (2015) and Eileen Rositzka (2015), respectively, zero in on the inherent misogyny and objectification of women in the Binder, Brownjohn, and Kleinman credits sequences.

There is general agreement that Binder's gun-barrel opening was a stroke of genius as a branding device, and as an extended, time-based logo for the series. Binder, following the lead of Saul Bass and other modernist designers in Hollywood, reconceptualized credits sequences as not just a way to identify the studio and its personnel, but also as a movie within a movie that visualized the film's narrative or thematic elements. Whereas classic studio credits were standardized to identify the studio rather than the film, Bass in the 1950s created specific title sequences for specific films, which influenced the whole industry. Robert Brownjohn and Saul Bass were both trained by students of László Moholy-Nagy, the Hungarian modernist designer, painter, photographer, filmmaker, sculptor and scholar who had brought Bauhaus design to the United States in the 1930s. Like Bauhaus designers, Bass organized his design elements asymmetrically on a mathematically precise grid, preferring sans serif type, and utilizing right and/or left justification (mirroring the screen's frame). The basis for a mathematical screen grid was the establishment of a horizontal and vertical axis, cutting the frame into four equally sized rectangles, which would allow Bass to create architectural structures within the two-dimensional screen space. Furthermore, modernist designers relied mostly on primary colors and blocks of color both to abstract the image and guide the viewer in the reading of text, even when title sequences were presented within a diegetic space (Horak 2014,122). Like Bass and Brownjohn, Binder was one of the first to demand credit for his work in titles, and, like them, he employed stylistic flourishes from modern and pop art, such as abstraction and psychedelic colors, to connote $1960 \mathrm{~s}$ modernity with its sexual liberation and visualization of violence.

This chapter analyzes the Bond titles, as well as providing a necessary ideological critique. Such an analysis will demonstrate that in keeping with modernist aesthetics, Binder utilized an extremely limited palette of formal devices, colors, and images. Furthermore, Binder's and Brownjohn's titles must be read for both their overt sexism through the objectification of woman's bodies, and for their utilization of disturbing racial stereotypes. While the titles of Kleinman and MK 12 are not free of charges of sexism, 
I argue that digitality abstracts their female bodies, de-eroticizing them and thereby limiting their voyeuristic spectacle. Furthermore, digital tools allow them to create post-modernist pastiches that brand both individual films and the series as a whole.

\section{The Opening}

The opening image of $\mathrm{Dr}$. No, a point of view shot through a gun barrel during which James Bond shoots at the audience, was considered so successful-along with Monty Norman's theme music - that it became the signature for the entire series. Indeed, nothing has contributed more to the branding of James Bond films than this opening image. Except for the very first Bond, $\mathrm{Dr}$. No, all other Eon Bond openings are structured as a three-part overture: the gun barrel, a narrative teaser sequence and the main titles. Varying in length between four and eight minutes, the action teaser is often only minimally connected to the film's main plot, sometimes ending as a kind of joke or surprise (Bennett and Woollacott 1987, 152), as when in From Russia with Love (UK: Terence Young, 1963) and You Only Live Twice (UK: Lewis Gilbert, 1967) Bond is seemingly killed. Other action sequences set up the villain, who Bond will be assigned to kill.

While the three-part opening sequence now seems conventional, given its continual repetition in the Bond canon, it was a completely new and original in the mid 196os, and effectively grabbed the viewer's attention. Common to all the films, the three-part opening focused obsessively on two themes: violence and sex, both addressing the audience viscerally and emotionally. The white dot that first appears on a black background and then finds James Bond walking along the screen's horizontal axis initially suggests either a camera, a spyglass or a gun scope. Bond seems to be in the cross hairs, and therefore subject to the viewer's control through the cinema's inherent scopic regime. The audience as voyeur-the circular view is surrounded by what looks to be a shutter-sees without being seen but is also placed in the subjective position of a potential Bond assassin. However, when James Bond turns, pulls his gun and fires at the audience, the tables are suddenly turned. The circle shakes a bit then slides vertically down the frame and fades out, with red blood filling the screen, as if the subject - the viewer-has been killed. The audience becomes the victim of violence, rather than the potential perpetrator, disarming them and making them pliable for further manipulation. The device recalls a trick in The Great Train Robbery (USA: Edwin S. Porter, 1903), where as a coda to the 
film, "Broncho Billy" Anderson shoots at the camera - the audience-as if to say that no one is safe even though the bank robbers have been caught. Highlighting the audience's voyeurism, and immediately punishing them for it, sets the stage for another motif that will become ever more prominent in subsequent titles: erotic titillations are often promised, but then frustrated by a fade out before the "action" begins.

\section{Dr. No-Main Title Design}

Unlike almost all subsequent Bond films, Dr. No's title sequence begins immediately after the gun barrel sequence: the black background is populated with a mosaic of flashing dots in various colors, green, baby blue and yellow. A somewhat larger red dot anchors the design, as "IAN FLEMING'S," appears in the right half of the frame. The smaller white dots below are then replaced with text on the vertical axis in pink and red that is four times larger: "DR. NO." The full title, then, forms a block that covers the whole lower right quadrant of the frame. In color and form, the block text resembles a Chinese chop or signature seal, implying that the villain of this piece is of East Asian extraction. As with a few other Bond villains, Dr. No (Joseph Wiseman) is subject to racial stereotyping.

The film's title then moves around the frame flashing on and off in different colors, as do colored dots around subsequent credits. The flashing dots not only mirror the gun barrel opening but also reference computer technology. Furthermore, the changing primary colors have a feel of pop art that, like the computer references, give the sequence a modernist look that was in keeping with much of the modern design work in the 196os. Two-thirds through the sequence, Binder cuts from the red dot to a red silhouette of a female dancer, followed by two more silhouetted dancers in orange and purple, accompanied by a vaguely African drum beat on the track. Unlike all subsequent Binder titles, the dancers are dressed, but the music marks them as Jamaican, changing colors from red hues to blue-green, their silhouettes overlapping as more major technical credits fade in and out. Planka $(2015,143)$ argues that the two women are Bond girls, while the male dancer, standing for Bond, asserts male control over the women.

They are replaced by black silhouettes of three blind men walking across the bottom of the screen, while the children's song, "Three Blind Mice," is sung with a calypso beat. After the director's credit, the silhouettes dissolve to live action shots of three black Jamaican blind men. Like Saul Bass, Binder understood that the titles "could act as a prologue," communicating 
both diegetic and non-diegetic information about the film to come (Horak 2014,94), although Binder eventually preferred generic rather than filmspecific references. However, the Dr. No's titles are oddly bifurcated between animated graphics - designed by Trevor Bond, who drew on his experience as a modernist animator-and moving images, between the modernity of computers and the implied racial Otherness of figures who prove to be a danger to Bond.

\section{Typography}

Another difference to Saul Bass's work can be found in Binder's and Kleinman's relation to the logocentricism of the titles. The primary raison d'etre for title sequences is to list the names of the creative personnel involved in a film, and the goal of the title designer is to make those words as legible as possible while holding the viewer's interest with visuals, which may at times overpower the typography. Bass conceptualized titles as a combination of visual elements, including typography, composition and layout, movement, color, and design, all of which contributed to the overall design of his film titles. Binder and Kleinman, on the other hand, seemingly eschew ascribing semantic meaning to their typography, the chop-like design of $D r$. No being the rare exception. Indeed, Binder's and Kleinman's typography and text placement remain unchanged throughout the Bond series: only $\mathrm{MK}_{12}$ innovates here in the titles for Quantum.

It becomes clear that while adhering to the geometry of modern graphic design, Binder was relatively uninterested in typography as a creative element. This may have been a function of Binder not having been trained as a graphic artist, unlike Saul Bass and Robert Brownjohn. As Pat Kirkham $(1995,12)$ notes, Binder used neither storyboards nor did he draw his own letters, instead relying on Letraset, a prefabricated rub-down typography. Like modernist designers, Binder composed his titles within a grid that divided the frame into four quadrants, placing his typography in relation to a central vertical and horizontal axis. Binder adheres rigorously to this grid for all of his Bond titles. While the titles to Dr. No still utilizes some left and right justification, Binder's later Bond titles avoid this design variable, creating credit blocks that are center justified. While left/right justification tends to stabilize the text within the frame, center justification tends to destabilize compositions, another method of manipulating the viewer. A constant in all the Bond titles was the use of small lettering on the left or above for credits, while names appeared in caps below or to the right of the 
center justified axis. Utilizing caps for names gives them a block quality that stands out from the busy background, especially since Binder relied exclusively on white typography for reasons of legibility, given that his live action and animated backgrounds were densely composed and filled with action. In keeping with the modernity of the James Bond project, Binder's use of clean, simple sans serif fonts, like Helvetica, Futura or Univers, mimics 1960 os American design.

It is Robert Brownjohn who first connects typography to voyeurism, when he projects credits on the gyrating body of a female belly dancer in From Russia with Love. Like Binder, he uses a modern sans serif type, but in various pastel shades rather than white, possibly to reflect the gypsy colors of the dancer. Brownjohn's Goldfinger returns to white typography on a black background, while a semi-naked woman in gold acts as a projection surface for images from the film. The titles promise eroticism and violent action, for example, in the scene where we see a gun go off in close-up: a sexualized trope for ejaculation.

\section{Color}

In keeping with modernist design, Maurice Binder used a limited palette of colors for his James Bond title sequences, consisting almost exclusively of primary colors: blue, red, yellow/orange, and green, plus black. Pastel shades are almost completely absent, except for a rare purple hue. Highly saturated primary colors are not only more visible, they also elicit stronger emotional responses, which is in keeping with the dramatic narratives. Binder utilized broad swatches of color, often filling the screen with monochromatic color, and then dramatically shifting from one color to another. These color fields act as a background for his moving silhouettes or other patterns, highlighting the movement of objects and persons while allowing Binder's uniformly white typography to pop off the screen, increasing legibility.

Of all the colors in the rainbow, Binder preferred blue. Indeed, twelve of fourteen Binder-titles are dominated by blue. In some sequences-Thunderball (UK: Terence Young, 1965), Moonraker (UK/France: Lewis Gilbert, 1979) or For Your Eyes Only (UK: John Glen, 1981) - blue reflects the blue of the sky or the sea, but in most cases, Binder's blue light communicates coolness, as in Octopussy (UK:John Glen, 1983) and A View to a Kill (UK: John Glen, 1985). James Bond films were nothing if not signposts for post-World War II modernity and cool. Given the on-going Cold War and the negative reputation of spies in the public imaginary in the early 1950s due to the 
Julius and Ethel Rosenberg trial in the United States and the defection of two British spies, Guy Burgess and Donald Maclean, in the United Kingdom, Bond offered a suave, modernist alternative. As a sexually liberated figure and a government licensed assassin, the Bond figure became an icon of modernity. Bond remains blasé to cheeky, depending on the actor, whether disposing of enemies or bedding resistant women. Blue encapsulates Bond's underlying coldness of emotion, masked by exuding calmness and tranquility in the face of mortal chaos. The blue titles for On Her Majesty's Secret Service (UK: Peter Hunt, 1969) and The Spy Who Loved Me (UK: Lewis Gilbert, 1977) refer to the Union Jack featured in the opening frames, but also communicate attributes such as loyalty, trust, and intelligence. "True blue" goes the phrase, representing qualities necessary for a secret agent.

If blue is often connected to "cool imagery," then red-oranges are hot colors, denoting fire, explosions, and gun fire. In Thunderball, for example, red fills the screen with every explosion and then returns to blue, while You Only Live Twice is primarily held in red-orange oranges to mimic the flowing lava while adding a touch of Orientalism. The red-oranges of fire also dominate Live and Let Die (UK: Guy Hamilton, 1973) and are associated with violence, death, and superstition. As a hot color, reds are connected to fire and blood, eliciting strong and even violent emotions such as passion and lust but also rage and danger. Red appears when Binder inserts explosions and fires but also indicates the danger of sexuality, as in his depiction of a backlit red hydra in Moonraker, or in the female bodies shooting from a gun in Octopussy. Bond's cool blue modernity, then, is juxtaposed to a red death, which is marked feminine.

Interestingly, red's complimentary opposite, green, makes a single appearance in almost every Binder-authored Bond title, beginning with Thunderball. Green is the color of spring, of the renewal of life, the color of the earth; it connotes youth, health, and vitality, but also projects safety and spiritual serenity. This might be Binder's reminder to his audience that in the unnatural world of Cold War espionage - a world of the violence and sexuality, of blue and reds-nature's green is not writ large but it does persevere.

The absence of all color is black, which Binder uses liberally in his palette. Obviously, black's primary utility is in silhouettes, Binder's most obsessive visual trope, as will be discussed below. Black hides details or highlights objects, creating uncertainty, as when black marks a gun barrel. Beginning with You Only Live Twice, however, Binder conceptualizes black as a field of color; first as a moving matte, then, in Diamonds Are Forever (UK: Guy Hamilton, 1971), as a full screen background: the diamonds on luxurious black velvet are 
replaced by specimens of naked young women, half-hidden in the darkness of the background. Every other Binder title, except The Spy Who Loved Me, utilizes black backgrounds, often to frame the women on display, contributing to the objectification of female bodies and to the furthering of audience scopophilia, just as the use of a limited palette of primary colors prepares the audience for further promises of violent action and sexual titillation.

\section{Film Techniques}

Given the obsessive sameness of many of the Binder produced title sequences, we can see these sequences as simple variations on a theme which carries over from one Bond film to the next, functioning primarily to brand the series. In each iteration, Binder works with the same set of visual themes but plays with their presentation by varying film techniques. As Pat Kirkham $(1995,12)$ notes, Binder got a lot of pleasure out of technology: "He was a ceaseless experimenter-with color (emulsions, filters), optical effects, underwater shots, slow motion, animation, electronic movement, superimposition and ways to blend or overlap images." However, these experiments are tested within a very limited formal parameter, including typography and color. There is also virtually no variation in the length of title sequences. The opening gun-barrel ran exactly 30 seconds, followed by the opening teaser scenes, and then the main title sequence, which was rigorously restricted to about three minutes, the median length for film titles in Hollywood. Interestingly, Daniel Kleinman's titles would average twenty-five seconds longer (as does MK 12's Quantum), except for GoldenEye, which at 2:54 minutes matches the Binder-title-average.

For Thunderball, Binder creates what appears to be a continuous singleshot-underwater-sequence, which utilizes animation to move silhouettes of swimming female nudes over live action bubbles exploding up to the surface, while the women are pursued by armed male scuba drivers, also in silhouette. You Only Live Twice adds graphic representations, multiple exposures, and traveling mattes to create a visual montage of naked women and flowing lava. On Her Majesty's Secret Service returns to animation and a martini-glass-matte, which features a montage of images from all the previous Bond films, allowing Binder to secure brand identity by connecting Sean Connery to George Lazenby. All other Binder titles utilize a combination of these techniques to create montages of naked women and guns.

The one technique that Binder employs in every one of his fourteen Bond titles is the animation of silhouettes. Binder had first applied silhouettes 
in his titles for Damn Yankees (USA: George Abbott and Stanley Donen, 1958), and colored silhouettes for $D r$. No, while all subsequent titles exploit black silhouettes. A dressed Bond in occasional silhouette contrasts with the habitual use of silhouetted naked women, emphasizing their erotic intent. Silhouettes made of black cut-out paper first became popular in the eighteenth century as an inexpensive form of portraiture, but the tradition of black figures in art goes back to ancient Greek pottery. Until the advent of photography, they were one of the few ways of creating an image of a person, other than having an artist paint or draw a portrait by hand. In photography, silhouettes created by the backlighting of persons and objects lose their function as portraiture and become methods to create atmosphere or to physically hide details. Silhouettes simplify and abstract compositions, a primary goal of modernist design, as evident in Man Ray and László Moholy-Nagy's camera-less photograms and Lotte Reininger's shadow animations. Furthermore, full-body silhouettes of naked women allow Binder to emphasize female anatomy without running into trouble with the censors, while also referencing nineteenth-century traditions of female portraiture (LeFever, 2009), turning what might be considered a tawdry voyeuristic moment into an aesthetic experience.

\section{Girls and Guns}

Maurice Binder famously summarized his credits sequences for the Bond films as "girls, guns, smoke, and steam" (King 2002; Raddatz 2012). In point of fact, it had been Robert Brownjohn's credits sequences for From Russia with Love and Goldfinger which set the sexual tone for all subsequent Bond titles. In almost all of the consecutive Bond title sequences by Maurice Binder, the dual tropes of female flesh and guns and of sex and violence become the obsessive poles around which the sequences are structured. Close-ups of hand-guns, invariably held by women, signal danger for the hero, but also remind viewers that Bond will not be afraid to bed them, even if they are working for the enemy.

A female hand points a gun directly at the credit "Sean Connery" in Diamonds, at the credit "Roger Moore as James Bond," in Live and Let Die, and at the credit for "Timothy Dalton" in The Living Daylights (UK: John Glen, 1987), while in The Spy Who Loved Me a silhouette of a Russian female points a gun at Bond's silhouette. These titles tell us: women with guns are dangerous and must be neutralized. In A View to a Kill, Grace Jones' screen credit seems to be shot from a gun, foreshadowing her role as May Day, 
the villain's deadly companion. Grace Jones is first seen wearing bright red outfits, again connecting the color to death and femininity. Girls with guns appear prominently in most other Binder titles as well. In fact, only three sequences do not feature close-ups of guns: You Only Live Twice, On Her Majesty's Secret Service, and Moonraker. In The Man With the Golden Gun (UK: Guy Hamilton, 1974), as befits the title, the golden gun points at Roger Moore's name above the title. Thus, guns in female hands function as a fetish for danger, death, sexual deviancy, and the violence that invariably ensues in James bond films. Every James Bond film features beautiful, young, gun-toting women who are themselves killers or working for the enemy, some of whom Bond can turn to after sex, some of whom he kills after off-screen penetration. The visual trope finds its tongue-in-cheek iteration in the image of a naked woman exercising on the horizontal bar of a gun barrel in The Spy Who Loved Me.

Binder's iconography consists of for more than go percent of images of naked women. As we have seen, Binder puts women on display and encourages a voyeuristic relationship to his sexualized images (Planka 2015,142 ). His ubiquitous silhouettes of female nudes never seem to tire of dancing, jumping, running, engaging in gymnastics, skiing, showing off breasts and hips. Binder's other strategy for the depiction of women is photographic, shooting frontal portraits, at times slightly distorted, or letting his camera caress body parts with slow moving pans, all of which recall the conventions of classic nudes in art production and centerfolds in Playboy, where Ian Fleming serialized On Her Majesty's Secret Service in 1963 (Hines 2018).

Furthermore, Binder's repeated use of tropes of sight and vision communicate and sanction a voyeuristic relationship, such as the close-ups of eyes in seven Binder titles, or the circular images of naked women (Moonraker), some seen through gun sights (Licence to Kill [UK/Mexico/ USA: John Glen, 1989]). In A View to a Kill, the woman knowingly looks at the camera - the audience — and thus exposes the viewer's voyeurism, but such moments are exceedingly rare. Binder reinforces erotic entanglement even further by guiding the audience's gaze to credits via eroticized body parts: in Diamonds Are Forever, a huge diamond covers a close-up of female genitalia behind Sean Connery's screen credit; in For Your Eyes Only John Glen's directorial credit is visible on a naked breast; Maude Adams' credit rests on the naked breast of a lying female nude (also holding a gun) in Octopussy; a female hand reveals half-naked breasts directly under the opening title credit in A View to a Kill. Here the audience as voyeur is guided by the typography. 
Beyond the undeniable sexism of the Binder titles, there is also the troubling aspect of racialized and racist images of women. Conceived in the era of 1970s "Blaxploitation," Live and Let Die's title sequence is particularly egregious, being structured as a "voodoo horror film." Cutting from the death of a British agent at the hands of some seemingly "primitive" black Jamaican cult_recalling countless racist Hollywood “jungle films" like Tarzan the Apeman (USA: W.S. van Dyke, 1932), where a white man is burned or cooked to death-Binder lays images of fire over naked and painted black women. In reference to James Snead's $(1994,4)$ notion of mythification, the white Bond needs black villains to highlight his whiteness:

Mythification involves the realization that film codes describe the interrelationship between images. American films do not merely feature this or that debased black image or this or that glorified white hero in isolation, but rather they correlate these images in a large scheme of semiotic evaluation [...]. This device engages audiences on the level of their racial allegiance, social background and self-image.

There is also the specific danger of women of color. One black female head becomes a wick for a torch of red fire, her eyes buggering out of her head-another well-worn racist trope (Snead 1994, 4) - the image intercut twice with a human skull. The fire motif continues over the silhouette of a naked black woman and multi-colored disembodied arms reaching for the sky, their silhouettes dancing, visually reinforcing references to "the occult." Black women are not portrayed as erotic but as signifiers of death. Binder's credits thereby undergird the mise en scene of the "voodoo rituals" in the teaser. Ironically, the only other time when Binder utilizes fire imagery as a design element (and not just for explosions) is in You Only Live Twice, where again women of color predominate: close-ups of Japanese women are juxtaposed to lava flows, conveying danger even in the silhouettes of naked geishas.

In A View to a Kill, we see an olive-skinned woman with red lips, who suddenly, after a lighting change to blacklight, appears in blackface with neon-red lips and colored body makeup, just as subsequent actresses appear in blackface with neon make-up. Their Otherness emphasizes the whiteness of the single woman in gun sight, while tropes of fire are connected to black female bodies to conjure up images of hell_-in keeping with the red-clad villain, played by Jamaican-American Grace Jones. The blacklight technology thus undergirds racist iconography. 
By the mid-1980s, at the height of the HIV/AIDS pandemic, when Binder completed his final Bond titles, the free and easy eroticism of the $1960 \mathrm{~s}$ was no longer modern. As British film critic Tom Shone $(1992,24)$ noted, Bond's obsolescence "was nowhere more lovingly observed than in the films' title sequences, shot by Maurice Binder." The availability of digital tools created a whole new universe of formal possibilities but also opportunities for Daniel Kleinman and MK12 to abstract the gun-and-girls tropes, their digital unreality undercutting any voyeuristic eroticism.

\section{Digital Shift}

Maurice Binder had used animation, traveling mattes, and superimpositions to layer his images of girls and guns behind the typography. Producing such montages necessitated careful planning and continual experimentation with exposures, since $35 \mathrm{~mm}$ negative film had to be exposed repeatedly for superimpositions. Mattes covered up parts of the frame while exposing others, again leading to multiple exposures. Setting exposure levels too high risked over-exposure, setting them too low left portions of the frame too dark. Furthermore, Binder's modernist methodology meant that he was composing for a two-dimensional frame, while multiple exposures further flattened out space.

By the time Daniel Kleinman was given the assignment to produce the titles for GoldenEye, computer generated imagery (CGI) had matured enough to create the first computer animated feature length animation, Toy Story (USA: John Lasseter, 1995). CGI allowed Kleinman, who had made a career for himself producing music videos and advertising films, not only to layer an almost infinite number of images without worrying about exposures, but also to grant him the ability to compose his titles in deep space. While multiple exposures of analog images were a matter of time consuming trial and error, digital tools allowed for image manipulations with a touch of the keyboard. Digitality engendered a post-modernist turn as well. Rather than simply juxtaposing iconic images composed within a mathematical grid, Kleinman created atmospheric sequences in highly synthetic spaces without regard for the rules of photographic realism or narrative logic: a phantasmagoria of floating objects. The digital paint-box also gave Kleinman and MK12 the freedom to manipulate color at 1000 points within the frame. They therefore eschewed broad color swatches for an ever-changing palette, depending on the moods they were trying to create. 
In GoldenEye, Kleinman's backgrounds of clouds and smoke change colors from bright orange to blue, grey, yellow and purple without influencing the objects in the foreground - another advantage of digitality. And while the titles for GoldenEye still feature a preponderance of nude women and guns, Kleinman's overall montage is focused on the visualization of the end of the Cold War. However, Kleinman's typography remains uninspired and monotonous, repeating similar fonts, sizes, and design. Except for GoldenEye, where Kleinman uses a yellow font, his standardized sans serif-typography sticks to standard white for legibility. There is indeed little variation in the overall text design of the post-Binder titles, except in MK12's titles for Quantum of Solace, which have a unique look. After a six-year hiatus in the series following Licence to Kill, Kleinman helped to reboot the Bond franchise in two ways. First, he updated Binder's gun-barrel-opening by reshooting the sequence in digital, adding much more detail to the previously dark interior of the barrel. More importantly, his titles for GoldenEye illustrate the new geopolitical context for Bond's secret agent work, symbolically visualizing the dissolution of the Soviet Union and thus mirroring the film's post-Cold War plot.

Kleinman's utilization of CGI technology becomes apparent from the very first image of his credits for GoldenEye, when the camera zooms out from inside a gun barrel, a bullet hurling forward towards the audience; then followed by a completely artificial, digital image as the camera turns into space: an impossibility in analog. The naked women posing in the fore, middle and background also originate in the digital, their bodies seemingly suspended in an orange-yellow cloud, possibly referring to the Soviet banner. These women are clearly products of computer animation, their focus sharp regardless of their distance from the implied camera, their contours and skin having the plasticine quality of CGI. Kleinman then suspends Communist sickles horizontally, transforming them into walkways for Bond and his naked women while hammers float through the frame, as if in a surrealist painting by René Magritte. Toppled statues of Vladimir Lenin and other Soviet leaders are destroyed with sledge-hammers by semi-clad women as far as the eye can see. Later, a woman in profile opens her mouth, releasing a gun barrel that fires: a digital image that Planka $(2015,145)$ mentions in her discussion of dangerous women, but it may also refer to such surrealist photography as Jaromir Funke's image of a man with a lightbulb in his mouth. A shower of hand-guns rises up with women dancing on their muzzles.

Just as the titles for GoldenEye are structured around visual tropes for the fall of Communism, so too do Kleinman's subsequent Bond titles develop 
visual motifs that reference film narratives playing out in an artificial digital space. As Kleinman (Radatz 2012) noted in an interview: "I am really riffing on a language already invented [...] but I do feel I've brought some individual creative input of my own to the titles and tried to make them more narrative and less just collage-like sequences." I would argue that Binder's collages of guns and girls have been supplanted by digitally sophisticated collages that return individualized narrative threads and a clear thematic focus to the Bond titles: their post-modernity references other Bond titles rather than the real world.

Thus, Tomorrow Never Dies (UK/USA: Roger Spottiswoode, 1997) opens with a homage to the stained glass warriors in Young Sherlock Holmes (USA: Barry Levinson, 1985) - the first feature-length film to incorporate CGI—and then continues as a meditation on digital technologies and on the media conglomerates controlling them, zooming through a matrix of numbers and creating human female forms from solid-state computer boards-all referencing the cyber war that ensues in the film. Indeed, Tomorrow Never Dies begins with an analog tail shot of what could be a Soviet-era MIG aircraft - reminding us of Bonds gone by — and then turns to digital to shatter the image before a rollercoaster ride on the logorhythmic highway ends with a seemingly analog image of (wo)men as insect-sized specimens on a slide, connecting the sequence to Binder's Bonds but also inferring that, in a virtual reality, humans have become insignificant.

The World Is Not Enough (UK/USA: Michael Apted, 1999) is structured around images of oil in keeping with a plot about an assassinated oil tycoon, whether visualizing partial female bodies sinking into or rising up from oil or depicting bodies dripping with crude. Kleinman's titles resemble a Binder title on steroids, erotically suspending female bodies in space, interrupted by firey explosions, yet these titles-impossible without CGI-use that technology to distance the viewer from affect. Die Another Day (UK/USA: Lee Tamahori, 2002) intercuts photorealistic images of Bond being tortured and beaten with CGI images of female bodies in fire and ice. Excerpts from the film-a strategy not seen since On Her Majesty's Secret Service-are shown and then digitally distorted in CGI sequences, which signify the villain's use of solar energy as a weapon of mass destruction.

For the series reboot with Daniel Craig, Casino Royale (UK/Czech Republic/USA/Germany/Bahamas: Martin Campbell, 20o6), Kleinman chooses a purely graphic representation of playing cards and roulette wheels, morphed from gun sights, which also reference the original cover design of Fleming's source novel (another return), while digital silhouettes of fisticuffs and gunplay between Bond and his adversaries result in guns firing black 
clubs and red hearts and corpses bleeding red hearts. It is a masterfully constructed space, featuring Lissajous spirals and other graphic elements that defy spatial orientation, recalling the ornate design of a deck of cards, which is then violated by flat red-and-black-silhouetted combatants who float in their own three-dimensional digital bubble. It is the only Bond sequence that eschews the visualization of naked women, focusing instead on card games and on Bond firing his weapon as a trope for Bond's poker game with the villain, Le Chiffre (Mads Mikkelsen). It is also the only title sequence that is wholly graphic rather than photographic, but its construction could only be achieved digitally.

For Quantum of Solace, MK12 created titles at the insistence of director Marc Forster. Founded in 2000, the design collective consisted of Jed Carter, Tim Fisher, Matt Fraction, Ben Radatz, Shaun Hamontree, and Chad Perry. Like Kleinman's titles, MK12's title relies on CGI technology, reprising GoldenEye's opening with a bullet shot from Bond's gun before moving through a desert landscape. However, MK12's titles are the first to rethink the presentation of the credits, utilizing moving graphic typography and a unique font. As in the Kleinman titles, the logic of digital animation-objects and scenes constantly morph into something else-rather than analog's realistic space-time coordinates guide the design. Interestingly, MK12's white, animated typography_lines form letters and words — is completely original, its sans serif-style mimicking the bullet's path. Likewise, MK12 significantly eliminates the voyeurism of female bodies, presenting mere apparitions of naked women that dissolve almost as soon as they appear, threatening only because of their size in relation to a CGI Bond moving or falling through amorphous desert landscapes. When naked female bodies appear that the end of the title, they are abstracted into kaleidoscope and silhouetted forms, referencing Binder as indeed virtually every MK12 image in some way refers to previous Bond title sequences, such as the parasol design in You Only Live Twice, the red moving dots from Dr. No. or the kaleidoscope image of women in On Her Majesty's Secret Service, with all of these now spectacularly reimaged as a digital praxinoscope.

Daniel Kleinman returned to the franchise for Skyfall (UK/USA: Sam Mendes, 2012). At the end of the prologue, Bond is shot and falls into a river, which allows Kleinman to structure his titles as a nearly continuous forward track through a CGI riverbed and other landscapes filled with objects of death and decay, some in stark black and white, others in flaming red (the bullet hole in Bond's chest) which again connotes death. Guns and girls do make an appearance but are abstracted in kaleidoscope images that include a skull morphing into a grave. Bond's impotent state is visualized through 
images of falling and shooting wildly at unseen targets without any effect other than to shatter mirrors, the fragmented glass a trope for schizophrenia or identity loss. Both Adele's theme song and Kleinman's dark, moody visuals reflect the many defeats Bond suffers in the movie, beginning with his own near-demise to the death of M (Judi Dench).

Finally, Kleinman's titles for Spectre (UK/USA/Austria/Mexico/Italy/ Morocco: Sam Mendes, 2015) feature for the first time a naked James Bond along with the proverbial nude Bond Girls. The credit sequence also animates a giant octopus, taken from SPECTRE's logo, as well as environments presaging the rogue syndicate's dark headquarters in an evocation of Ken Adam's modernist set designs for the 1960 s Bond films. As in Skyfall, Bond falls through space, his nakedness a sign of vulnerability but also strength-fire can't touch him -, thus revitalizing the weak oo7 of Skyfall. Kleinman's titles, then, construct a Freudian nightmare with images that are both erotic and horrific, the black octopus enveloping a woman's naked body like a giant phallus, which is subsequently contrasted with images of fire and death. It is another surrealistic dream filled with dark shadows, the camera traversing empty spaces that evoke Giorgio de Chirico and M.C. Escher while a montage of eyes carries strong connotations of Fritz Lang's Metropolis (Germany: Fritz Lang, 1927).

Except for Die Another Day, none of the Kleinman titles incorporate shots from the films, but even there, the images of Bond's torture are highly stylized and abstracted by digital electronic females dancing while conjuring up a simulacrum of eroticism. Kleinman and MK12 prefer a set of iconic images in order to brand the series and individualize each film. Digital female forms appear as transparent liquids, as oil, as computer circuits, as molten steel or as disembodied parts for moving kaleidoscope designs. In doing so, they frustrate the voyeuristic male gaze. Planka (2015, 147) argues that these female bodies are surfaces for the projections of the male gaze, but I would suggest that the lack of flesh and blood negates their erotic appeal. The overt voyeurism of Binder's titles is eliminated by placing a heavier emphasis on violence and on the threat of a death of the hero.

While Kleinman moves beyond the simple binary of Binder's guns and girls, his and MK12's titles employ iconic images to introduce themes and codify plots. When guns and girls do appear, they are imbedded in dreamscapes, with objects floating freely in digital spaces that have no visible coordinates but only exist in a digital no-man's land, thereby robbing them of any erotic power. The utilization of CGI and digital post-production allows Kleinman and MK12 to create densely composed, $3 \mathrm{D}$-like views of unreal 
spaces that morph with a speed that leaves the audience overwhelmed, thus making them vulnerable for further manipulation in a vein similar to Binder's gun barrel sequence. Rather than manipulating the viewer with photographically realistic images of eroticized female forms, these digital titles recreate the sensory overload of music videos to reproduce their excitement and reference their modernity. After all, the goal of the Bond franchise continues to be to entertain the audience by allowing them to identify with a hero who has a license to kill but is also continuously under mortal threat.

\section{Conclusion}

This chapter has addressed the aesthetics and cultural politics of the James Bond title sequences and their repeated use of technologies, techniques, and imagery as well as their tenuous depictions of gender and race. Working in the analog realm and repeating recognizable tropes and images, Maurice Binder's work stands out against countless other films from the period, which simply begin the plot behind the titles, in that Binder's sequences function to brand the series rather than individual films. In that endeavor, Binder utilized a limited number of visual tropes of young women in sexualized positions and of guns leading to violence. His overt use of sexualized and racialized imagery was presented in primary pop art colors as a montage in a two-dimensional space, which marked his titles as modernist. Individual films were branded by giving each title sequence its own theme song that could be sold in conjunction with the film. Such a strategy seems to have been in the interests of the Eon producers, who were always thinking beyond the production of a single film. In that sense, the Bond titles are successful as series branding.

Digitality has allowed for a much more complex layering of images, undergirding the branding of the film series as well as the referencing of film-specific narratives and themes. Kleinman and MK12 imbue each title with a specific mood and utilize iconic visual images and scenes that refer to the specific storylines that follow. In particular, digital tools have completely altered the construction of space. Rather than maintaining realistic space-time coordinates, the post-analog titles construct free-floating spaces where metaphoric and real objects and persons appear and disappear, creating the violent and erotically charged dreamscapes that Binder always aspired to. In the process, the voyeurism of Binder's nudes is mitigated, de-eroticizing female bodies into post-modern algorithmic visual surfaces. 


\section{Works Cited}

Bennett, Tony, and Janet Woollacott. 1987. Bond and Beyond: The Political Career of a Popular Hero. New York: Methuen.

Brosnan, John. 1981. James Bond in the Cinema, Second Edition. San Diego: A.S. Barnes \& Co.

Cork, John, and Bruce Scivally. 2002.James Bond: The Legacy. New York: Harry N. Abrams.

Hines, Claire. 2018. The Playboy and James Bond: oo7, Ian Fleming and Playboy Magazine. Manchester: Manchester University Press.

Horak, Jan-Christopher. 2014. Saul Bass: Anatomy of Film Design. Lexington: University Press of Kentucky.

Hunt, Kristin. 2011. "Beyond the Spiral Barrel: A Critical History of Dance in the James Bond Films.” In James Bond in World and Popular Culture: The Films are Not Enough, edited by Robert G. Weiner, B. Lynn Whitfield, and Jack Becker, 6o-75. Newcastle upon Tyne: Cambridge Scholars Publishing.

Kirkham, Pat. 1995. "Dots and Sickles." Sight and Sound5, no. 12 (December): 10-12. LeFever, Gregory. 2009. "Faces in Black and White." Early American Life, June, 6o-9. Planka, Sabine. 2015. "Female Bodies in the James Bond Title Sequences." In For His Eyes Only: The Women of James Bond, edited by Lisa Funnell, 139-45. New York: Wallflower.

Radatz, Ben. 2012. "James Bond: Fifty Years of Main Title Design." Art of the Title, Accessed September 6, 2017, http://www.artofthetitle.com/feature/james-bond50-years-of-main-title-design/.

Rositzka, Eileen. 2015. "Random Access Mysteries. James Bond and the Matter of the Unknown Woman." In For His Eyes Only. The Women ofJames Bond, edited by Lisa Funnell, 146-6o. New York: Wallflower.

Shone, Tom. 1992. "It's Time To Junk Bond." In The Sunday Times, October 25, 24.

Snead, James. 1994. White Screens/Black Images: Hollywood From the Dark Side. London: Routledge.

\section{About the Author}

Jan-Christopher Horak received his PhD. from the Westfählische WilhelmsUniversät in Münster, Germany, his MS from Boston University, and a BA from the University of Delaware. He was previously Director of UCLA Film \& Television Archive, Director of Archives \& Collections, Universal Studios, Director, Munich Filmmuseum, and Senior Curator, George Eastman Museum. He has held professorships in Rochester, Munich, Salzburg, and 
Los Angeles. An Academy Scholar in 2006, he is recipient of the Katherine Singer Kovacs Essay Award (2007), SCMS Best Edited Collection Award (2015), the Andor Kraszna-Kraus International Film Book Award (2016), and the Reinhold Schünzel Prize (2018). His books include: Saul Bass. Anatomy of Film Design (2014), L.A. Rebellion: Creating a New Black Cinema (2015), and Hollywood Goes Latin. Spanish-Language Filmmaking in Los Angeles (2019). 